\title{
Dynamics of physical trail construction and of trail usage in the leaf-cutting ant Atta laevigata
}

\section{Sofia Bouchebti, Raphael Vacchi Travaglini, Luiz Carlos Forti \& Vincent Fourcassié}

To cite this article: Sofia Bouchebti, Raphael Vacchi Travaglini, Luiz Carlos Forti \& Vincent Fourcassié (2019) Dynamics of physical trail construction and of trail usage in the leaf-cutting ant Atta laevigata, Ethology Ecology \& Evolution, 31:2, 105-120, DOI: 10.1080/03949370.2018.1503197

To link to this article: https://doi.org/10.1080/03949370.2018.1503197

册 Published online: 13 Aug 2018.

Submit your article to this journal

III Article views: 53

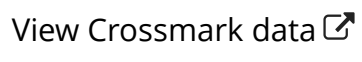

Citing articles: 1 View citing articles $\widetilde{ }$ 


\title{
Dynamics of physical trail construction and of trail usage in the leaf-cutting ant Atta laevigata
}

\author{
Sofia Bouchebti ${ }^{1}$, Raphael Vacchi Travaglini $\mathbb{B}^{2}$, Luiz Carlos Forti $^{2}$ \\ and VINCENT FourCassié (iD ${ }^{1, *}$ \\ ${ }^{1}$ Centre de Recherches sur la Cognition Animale, Centre de Biologie Intégrative, Université \\ de Toulouse, CNRS, UPS, Toulouse 31062, France \\ ${ }^{2}$ Laboratorio de Insetos Sociais Pragas, UNESP, Faculdade de Ciências Agrònomica de \\ Botucatu, Departamento de Produção Vegetal, Fazenda Experimental Lageado, P.O. Box \\ 237, 18610-307 Botucatu, SP, Brazil
}

Received 12 March 2018, accepted 26 June 2018

Leaf cutting ants of the genus Atta build long lasting physical trails to exploit the vegetation around their nest. In this paper we investigated the dynamics of physical trail construction and usage in the leaf-cutting ant Atta laevigata. We assessed the average duration of physical trail construction in a pasture environment and estimated the impact of the change in the physiognomy of the terrain on ant speed, individual gross transport rate and rate of resource collection by taking into account the effects of confounding variables for each of these parameters. We also examined whether ants are able to adjust their foraging behaviour at the individual or collective level in order to maintain the same rate of vegetation return to their nest along the construction process. We found that a colony of A. laevigata needs between $4 \frac{1}{2}$ and $61 / 2$ days to complete a physical trail. The construction proceeded in a fairly uniform manner along the trail, suggesting that it is not the result of the coordinated action of a small group of specialized individuals progressing along the trail but rather of the sum of uncoordinated actions of individual workers. Ant speed increased by a 2.6 factor on a cleared trail compared to an uncleared trail and individual gross transport rate nearly doubled. However, there was no significant change along the construction process in traffic intensity, the proportion of ants returning to the nest with a piece of vegetation or the rate of resource delivery to the nest. The main benefit of trail construction is thus to mobilize less foragers on the trail to collect the same amount of food, leaving the possibility for the remaining workers to forage on other trails or to accomplish other tasks.

KEY WORDS: leaf-cutting ants, foraging, construction, load transport, locomotory speed.

\footnotetext{
"Corresponding author: Vincent Fourcassié, Centre de Recherches sur la Cognition Animale (CRCA), Centre de Biologie Intégrative (CBI), Université de Toulouse, CNRS, UPS, Toulouse 31062, France (E-mail: vincent.fourcassie@univ-tlse3.fr).

Present address for Sofia Bouchebti: Department of Entomology, Hebrew University of Jerusalem, P.O. Box 12, Rehovot 76100, Israel.
} 


\section{INTRODUCTION}

Moving from one point to another requires much less effort when one walks on a smooth rather than on a rugged surface. Hence, when given the choice among several routes offering surfaces of different physical complexity, animals generally prefer to make a detour and travel along the route that offers the less physically complex surface or that is less energy demanding (Shepard et al. 2013; Halsey 2016). For example, ants that live in forest environments prefer to move along lianas and fallen branches, even if by doing so they increase the distance they travel, because these structures offer a relatively smooth surface compared to the leaf litter on the forest soil (Farji-Brener et al. 2007; Loreto et al. 2013; Freeman \& Chaves-Campos 2016) or to the rugged surface of the tree bark (Clay et al. 2010). To decrease their locomotor effort animals that travel regularly in their home range along the same routes can also build physical trails, i.e. pathways that are cleared of obstacles. In most animals, however, these trails are the result of a passive process due to the trampling of the vegetation (Bates 1950; Blake \& Inkamba-Nkulu 2004). Only humans and ants are known to actively build physical trails. In ants, these structures, also called trunk-trails, are generally observed in species that form big colonies and that transport external loads, such as seed-harvesting ants (Lopez et al. 1993), wood ants (Gosswald 1943) or leaf-cutting ants (Shepherd 1982). These trails are actively maintained (Cevallos Dupuis \& Harrison 2016) and they can persist for several months, or even years in some ant species (Stäger 1936; Chauvin 1962; Kost et al. 2005).

Because they offer a relatively even surface, the use of trunk-trails allow ants to increase their speed (Rockwood \& Hubbell 1987; Fewell 1988; Sales et al. 2015; Bochynek et al. 2017) and, probably - this has actually never been measured - to decrease the energetic cost of transport (Halsey 2016). Based on an estimation of the energetic cost of load transport, Howard (2001) showed that in leaf-cutting ants of the genus Atta the cost of construction and maintenance of physical trails may be relatively low compared to the huge number of workers in the colonies. Despite this low cost however, Bochynek et al. (2017) showed through a model of trunk-trail profitability that, depending on the speed gain of walking on a more even terrain, the proportion of unladen workers in the flow of ants returning to their nest and the proportion of these workers taking part in trail maintenance tasks, the construction of physical trails may not always be energetically profitable for the colonies. In fact, for some combinations of the values of these parameters, the amortization time required to balance the costs of construction and maintenance of physical trails may sometimes take several months. The amortization time may also vary with the time required for trail construction, a factor that is not taken into account in Bochynek et al. (2017)'s model. In fact, for the sake of simplification, their model assumes that food collection starts after the completion of the physical trail. In ants however, food collection starts as soon as the first recruited workers reach the food. Trail construction thus occurs in the same time as food collection and this may change the pattern of trail profitability and the time required for the trail to be amortized. In particular, without any adjustment of their foraging behaviour, the net benefit of the trail for the ants should be much lower at the beginning of the trail construction because of the reduced speed of the ants and of the cost of trail construction.

In this paper, we first assess the time required to build a physical trail by colonies of the leaf-cutting ant Atta laevigata living in pastures. We then examine the way the trail construction proceeds. We tested whether the construction of a trail is oriented, 
progressing as a moving front from the proximal end to the distal end, much alike the construction of a road through bulldozing by humans, or whether it proceeds by successive stages over the whole length of the trail, in the same way as a footpath through a cluttered environment that is progressively enlarged by travelling pedestrians. Finally, we investigate whether ants are able to adjust their foraging behaviour at the individual and/or collective level throughout the different stages of trail construction so as to compensate for the cost of trail construction and maintain the same substrate delivery rate. This could be done in a number of ways, e.g. by increasing traffic intensity or foraging efficiency, i.e. the proportion of ants returning to the nest with a leaf fragment, or by increasing the size of the leaf fragments collected (through an increase of the average size of the workers or through an increase of the relative size of the loads collected by ants). For each stage of trail construction we measured the traffic intensity, the foraging efficiency, the average size of the ants and the average mass of the load they transport. All these parameters were corrected for confounding variables to isolate the impact of the state of the terrain at each stage of trail construction. The impact of the state of the terrain on foraging performance at the level of individual foragers was assessed by computing the gross transport rate (Traniello \& Beshers 1991; Cerdá et al. 2009), i.e. the product of the speed of the ants by the mass of the load they carry, and at the collective level by the substrate delivery rate, i.e. the amount of vegetation retrieved to the nest per minute.

\section{MATERIALS \& METHODS}

Species studied and study area

Four mature colonies of Atta laevigata located in a pasture near the campus of UNESPBotucatu, state of Sao Paulo, Brazil (22 $\left.50^{\prime} 46^{\prime \prime} \mathrm{S}, 48^{\circ} 26^{\prime} 02^{\prime \prime} \mathrm{W}\right)$, were used in this study. A. laevigata is a species of leaf-cutting ant with a wide distribution in South America (Delabie et al. 2011). It builds huge underground nests (Moreira et al. 2004) and collects both dicotyledons and monocotyledons (Fowler et al. 1986) in the environment surrounding its nests.

\section{Data collection}

All experiments were carried out during the humid season, between October 2012 and January 2013. At this time of the year the foraging activity is essentially nocturnal (Amante 1972). The experiments thus started at the beginning of the night, between $7 \mathrm{pm}$ and $9 \mathrm{pm}$.

Before the beginning of the experiments, four successive stages, corresponding to the different stages of physical trail construction, were defined (Fig. 1). The first stage corresponds to the laying of a chemical trail, before the beginning of trail construction. At this stage no physical trail yet exists and a trail can be distinguished only because of the continuous flow of ants that follow the chemical trail. The second stage corresponds to the beginning of the trail construction: the vertical grass blades along the chemical trail have been cut and only the green horizontal grass blades remain. In the third stage, all green grass blades (vertical and horizontal) have been cut and only the dry grass mat in contact with the soil remains. The fourth and final stage corresponds to a trail completely cleared of vegetation but in which some rootstocks that are too big for the ants to cut come up to the surface (stage 4a) or to a trail in which the bare soil is exposed (stage 4b) (Fig. 1).

As the vegetation cover in the pasture was not uniform, parts of the physical trails whose construction was monitored could happen to cross patches of bare soil or soil with exposed rootstocks, corresponding to the final stage of trail construction. To assess the average proportion 


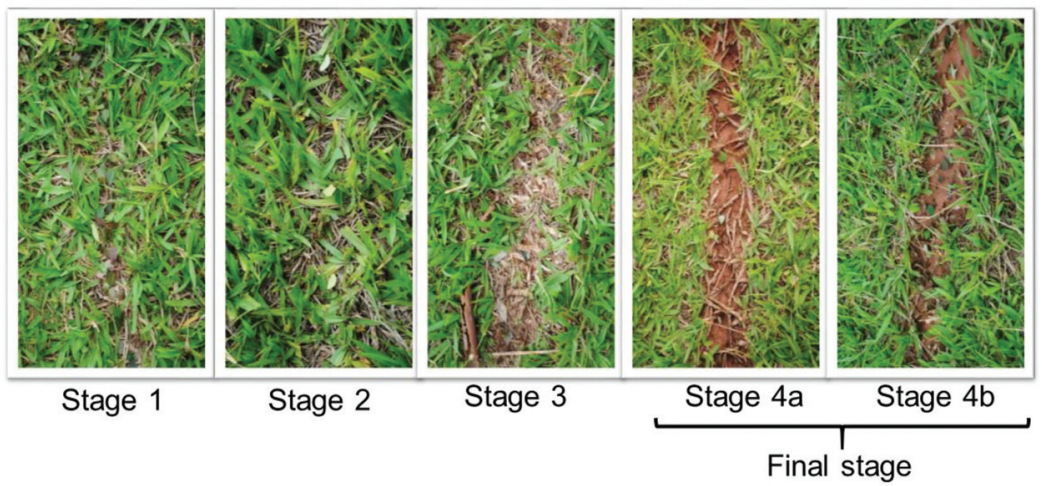

Fig. 1. - Illustrations of the different stages of the construction of a physical trail in the leaf-cutting ant Atta laevigata. Stage 1 corresponds to a chemical trail, before the initiation of any construction work. In stage 2 the vertical grass blades along the chemical trail have been cut and only the green horizontal grass blades remain. In stage 3 , all green grass has been cut and only the mat of dry grass in contact with the soil remains. Stage $4 \mathrm{a}$ and $4 \mathrm{~b}$ correspond to a trail completely cleared of vegetation but in which some rootstocks that are too big for the ants to cut come up to the surface (stage 4a) or to a trail in which the bare soil is exposed (stage 4b).

of trail length that corresponded to this stage before the initiation of trail construction, we traced $503 \mathrm{~m}$-long transects at randomly chosen places in the pasture and measured the proportion of the length of these transects covered by bare soil or soil with exposed rootstocks. To evaluate the state of a fully completed physical trail, we measured the average proportion of trail covered by bare soil or soil with exposed rootstocks on $24,3 \mathrm{~m}$-long sections along well-established physical trails. To ensure that these trail sections corresponded to the maximum traffic intensity, they were chosen close to the beginning of the trails, before any bifurcations occur.

To initiate the construction of a new trail, a pile (about $500 \mathrm{~g}$ ) of Acalypha wilkesiana leaves, a very attractive substrate for leaf-cutting ants which was absent from the pasture in which the nests were located, was placed at $3 \mathrm{~m}$ from an active trunk trail. Once this new resource was discovered and a more or less continuous flow of ants between the active trunk trail and the leaf pile could be distinguished, the outline of the new trail was marked every $20 \mathrm{~cm}$ with wood sticks.

We monitored the construction of the trail every hour during the first $4 \mathrm{hr}$ of trail construction. We then made two observations per day, one in the morning and another at the beginning of the evening. To avoid substrate depletion the pile of Acalypha leaves was regularly renewed (usually 3 times a day). The trail was divided in 5-cm sections and at each monitoring time, each section was assigned one of the four construction stages defined above. Observations stopped whenever at least two-thirds of the trail length had been assigned the fourth and last stage of trail construction or after 4 days maximally. In total, the construction of 20 trunk trails was monitored.

To measure the impact of the state of the terrain corresponding to each construction stage on the various components of foraging behaviour, we selected five $50-\mathrm{cm}$ long sections of active foraging trails whose appearance corresponded to each of the construction stage. One hundred individuals were then followed on each of these sections. Only ants that did not stop or make U-turns were taken into account. The air temperature was noted for each ant followed.

For each construction stage the following variables were measured: ant speed, ant mass, load mass, traffic intensity, foraging efficiency, individual gross transport rate (GTR). To measure the average speed of the ants, the time required for each ant to cross the whole $50 \mathrm{~cm}$ section of trail was noted. Then, each ant and its respective load were collected and gently placed in an individually labelled vial filled with alcohol. Back in the lab the contents of each vial was transferred in an Eppendorf which was placed in a dry oven at $50{ }^{\circ} \mathrm{C}$ during 3 days. The ants and their 
respective loads were then weighed. To allow comparison between ants of different sizes, load mass was expressed as loading ratio i.e. (ant mass + load mass)/load mass.

To assess the intensity of traffic on the trail, the number of ants (distinguishing between laden and unladen ants) crossing an imaginary line in the middle of the 50-cm trail sections was counted during 1 min every 20 ants that were followed, i.e. we had five counts per construction stage. Foraging efficiency was computed as the proportion of ants returning to the nest with a leaf fragment. Following Traniello and Beshers (1991), GTR was assessed with the following formula: GTR = ant speed $(\mathrm{cm} / \mathrm{s})$ * load mass (mg). Finally, the foraging performance of ants at the collective level was assessed by computing the substrate delivery rate, i.e. the amount of vegetation retrieved to the nest per minute.

\section{Statistical analysis}

The change over time in the proportion of trail covered by the last stage of trail construction (fourth stage, corresponding to a trail completely cleared of herbaceous vegetation) was investigated by using a binomial mixed model with time as fixed factor and trail entered as a random factor. The 95\% confidence interval of the model predictions was calculated using a method described in Zuur et al. (2015). The variance explained by the model was assessed by the marginal and conditional $R^{2}$ for GLMM (Nakagawa \& Schielzeth 2013).

To investigate whether trail construction proceeds as a moving front or in successive stages throughout the whole length of the trail, a number corresponding to the construction stage identified at each monitoring time was assigned to each $5 \mathrm{~cm}$ section of the trail (1 for stage 1,2 for stage 2 , etc.) and the mean of these numbers was calculated over the whole observation period for each trail section. A Spearman rank correlation coefficient was then calculated between these mean values and the rank of the section along the trail, beginning from its proximal end. A significant negative correlation would indicate that the construction proceeds from the proximal to the distal end of the trail.

We used the same method to investigate the impact of construction stage on all response variables, namely: ant speed, loading ratio, GTR, ant mass, traffic intensity, foraging efficiency and substrate delivery rate. We constructed all possible models that included the factors that are known to have an effect on these variables (Table 1) and then used a model averaging procedure (Burnham et al. 2011) to compute an average model from the set of models with AICc differences $<7$. We then calculated the response variables from the equation of the average model with the effects of the confounding factors removed. The corrected values of the response variables were then compared between construction stages with a GLM followed by a post-hoc Tukey test. The type of GLM used for each studied variable is indicated in Table 1. To estimate model fit for the quasi-Poisson and quasi-binomial GLM, a pseudo- $R^{2}$ was calculated as the ratio of the deviance of the model on the null model.

Square root or log transformations were applied to the variables whenever this could improve the homoscedasticity and normality of the model residuals. All statistical tests were run, and the graphics generated, with R 3.1.3 (R Development Core Team 2015). We used the R package MuMIn (Barton 2016) for the model averaging procedure and the package multcomp (Hothorn et al. 2008) to perform the post-hoc Tukey test. The numbers indicated in brackets in the text give the $95 \%$ confidence interval of the mean.

\section{RESULTS}

\section{Dynamics of trail construction}

Trail construction occurred each time ants discovered the pile of Acalypha leaves near an active trail. However, the time it took for the discovery and the initiation of recruitment to the leaves was highly variable ranging from 10-15 min to several hours. 
Table 1.

The effect of trail construction stage on each studied variable was investigated by a GLM after correcting for confounding factors. The type of GLM used for each studied variable is indicated in the third column. Gross Transport Rate is the product of ant speed by load mass, both corrected for their confounding factors. Foraging efficiency is the proportion of ants returning to the nest with a leaf fragment. Substrate delivery rate is the amount of vegetation biomass retrieved to the nest per minute. The footnotes list the papers in which the effect of each confounding factor was demonstrated.

\begin{tabular}{|c|c|c|}
\hline Studied variable & Confounding factors & Type of GLM \\
\hline Ant speed $\left(\mathrm{cm} \cdot \mathrm{sec}^{-1}\right)$ & $\begin{array}{l}\text { Temperature }^{1} \text {, ant mass } \\
\text { traffic intensity }\end{array}$ & Gaussian \\
\hline Loading ratio & Temperature $^{5,6}$, ant mass ${ }^{5,6}$ & Gaussian \\
\hline Gross Transport Rate (mg.cm. sec $^{-1}$ ) & $\begin{array}{l}\text { Temperature, ant mass, loading ratio, } \\
\text { traffic intensity }\end{array}$ & Gaussian \\
\hline Ant mass (mg) & Temperature $^{6}$ & Gaussian \\
\hline Traffic intensity (ants.min ${ }^{-1}$ ) & Temperature $^{7}$ & Quasi-Poisson \\
\hline Foraging efficiency & Temperature $^{8}$ & Quasi-binomial \\
\hline Substrate delivery rate (mg. $\left.\mathrm{min}^{-1}\right)$ & Temperature & Gaussian \\
\hline
\end{tabular}

${ }^{1}$ Hurlbert et al. (2008)

${ }^{2}$ Burd (2000)

${ }^{3}$ Rudolph and Loudon (1986), Zollikofer (1994), Gissel Nielsen (2001)

${ }^{4}$ Burd and Aranwela (2003)

${ }^{5}$ Wetterer (1990)

${ }^{6}$ Burd (1996)

${ }^{7}$ Lewis et al. (1974)

${ }^{8}$ Caldato et al. (2016)

Once the recruitment was launched, trail construction began rapidly (Fig. 2). Only 6\% of the total trail length changed from stage $4 \mathrm{a}$ (trail with exposed rootstocks) to stage $4 \mathrm{~b}$ (trail with bare soil) within the 4-day observation period, showing that ants have a hard time to cut the rootstocks across their trails and that, along with stage $4 \mathrm{~b}$, stage $4 \mathrm{a}$ corresponds, as we assumed, to a final stage of trail construction. Within the 4-day observation period one trail out of 20 never went beyond the third construction stage (and was thus removed from the database used for our model of trail construction duration), 16 trails were partially achieved, and three trails reached the state of a fully completed physical trail. Based on an extrapolation of the model beyond the observation range, one can predict that a physical trail requires on average approximately $5 \frac{1}{2}\left[4_{1}^{1 / 2}-6 \frac{1}{2}\right]$ days to be completed (Fig. 2). The width of the trails was about $5 \mathrm{~cm}$ and did not change much after stage 2 .

Fig. 3 shows that the initial state of the terrain for the $1 \mathrm{st} \mathrm{m}$ of the trail corresponded to more advanced construction stage compared to the rest of the trail. This can probably be explained by the fact that trail construction had already begun at the time of our first observation. The mean score of the final construction stage was fairly uniform for the 1st and 2nd $\mathrm{m}$ of the trail but slightly declined for the 3rd m (Fig. 3), indicating that the construction work progressed more slowly for the last part of the trail. This is confirmed by the fact that there was a significant negative correlation between the mean score of construction stage and the rank of the sections along the trail for 18 out of 20 trails studied. 


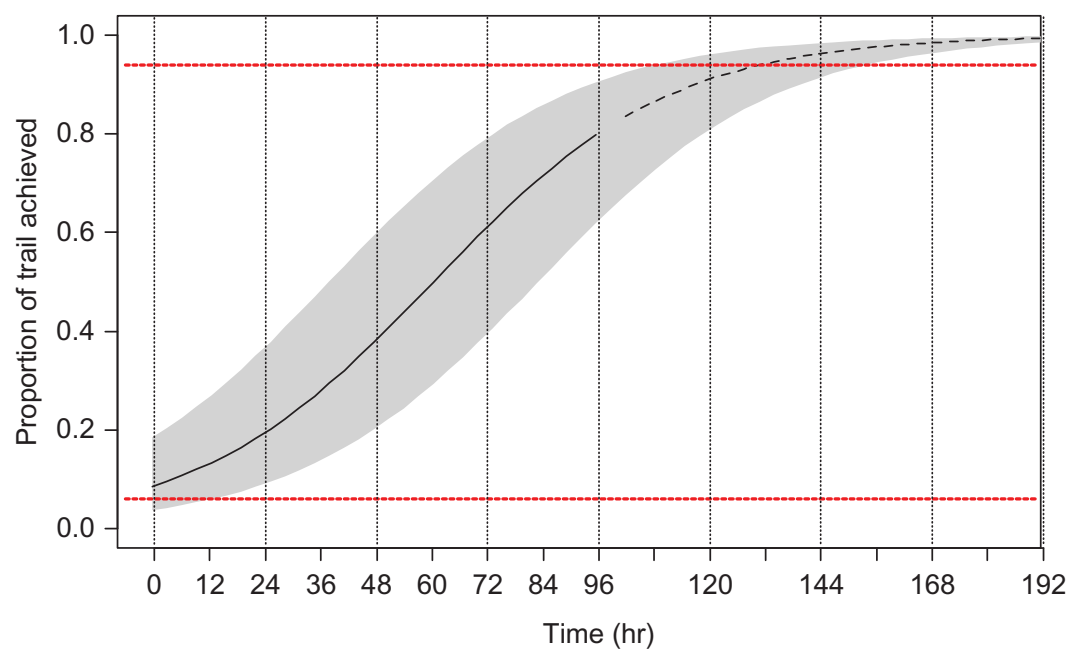

Fig. 2. - Change over time of the proportion of trail length corresponding to the final stage of trail construction, i.e. stage $4 \mathrm{a}$ or $4 \mathrm{~b}$ in Fig. 1. The trails were about $3 \mathrm{~m}$ in length. The predictions from a binomial GLMM $\left(R^{2}\right.$ marg $=0.368, R^{2}$ cond $\left.=0.745\right)$ are indicated by a black continuous line (the dashed line corresponds to extrapolation) and the $95 \%$ confidence interval of the predictions by the grey zone. The lower and upper horizontal dashed lines correspond respectively to the mean proportion of transect length covered by stage 4a or $4 \mathrm{~b}$ on $24,3 \mathrm{~m}$-long transects chosen at random location in the pasture and to the mean proportion of trail length corresponding to stage $4 \mathrm{a}$ or $4 \mathrm{~b}$ on $3 \mathrm{~m}$ sections of well-established physical trails. $N=19$ trails.

\section{Impact of trail construction on foraging behaviour}

Ant speed increased with increasing body mass, temperature and traffic intensity, and decreased with increasing loading ratio. Once these effects were removed, we found that speed increased monotonically with the progression of the physical trail construction (Fig. 4A; GLM: $F_{4,492}=170.17, P<0.001, R^{2}=0.58$ ).

Loading ratio decreased with both increasing ant mass and temperature. Once these effects were removed, we found a significant overall effect of construction stage on this variable (Fig. 4B; GLM: $F_{4,492}=170.20, P<0.001, R^{2}=0.58$ ). However, the posthoc test shows that there was no monotonic pattern in the variation of the mass of the leaf fragments transported. The monotonic increase observed in individual GTR with the progress of trail construction (Fig. 4C; GLM: $F_{4,492}=28.95, P<0.001, R^{2}=0.18$ ) was thus due essentially to the increase in locomotory speed.

Ant mass increased with increasing temperature. When this effect was removed, no effect of trail construction on the distribution of ant mass could be revealed (GLM: $\left.F_{4,492}=2.026, P=0.089, R^{2}=0.01\right)$.

Since temperature had no effect on traffic intensity and on foraging efficiency the effect of trail construction was investigated on the raw values of these variables. We found that trail construction stages had no significant effect on traffic intensity (Fig. 5A; GLMz: $F_{20,24}=0.712, P=0.590$, pseudo- $R^{2}=0.12$ ) but significantly impacted foraging efficiency (Fig. 5B; GLMz: $F_{20,24}=5.625, P=0.003$, pseudo- $R^{2}=0.52$ ). Foraging efficiency was low when no physical trail yet existed (stage 1) and then increased as soon as the vertical grass blades along the trail had been cut (stage 2). However, it was not significantly different between the initial and final stage of trail construction. The 


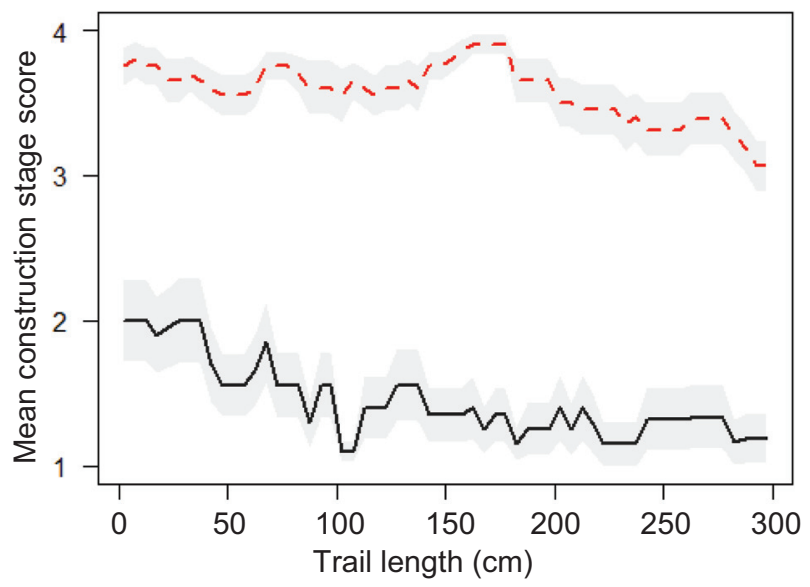

Fig. 3. - Progression of the construction work along the trail. Mean score of the initial (continuous line) and of the final (dashed line) construction stage of the terrain along the length of the trails. The 95\% confidence interval of the mean is indicated by the grey zone. $N=20$ trails.

substrate delivery rate was not significantly affected by the state of the terrain (Fig. 5C; GLM: $F_{20,24}=2.267, P=0.097$, pseudo- $\left.R^{2}=0.31\right)$.

\section{DISCUSSION}

Atta laevigata workers initiated the construction of a trunk trail each time a new resource was placed near an active trail. Ants began cutting the vegetation as soon as a chemical trail was established. The outline of the trail did not change thereafter. The duration of trail construction took on average $51 / 2[41 / 2-61 / 2]$ days. This should be considered as a minimum estimate since in our experiment the traffic intensity was maintained at a high level throughout the duration of trail construction by regularly renewing the heap of vegetation at the end of the trail. In natural conditions traffic intensity probably slowly decreases with time because of the depletion of the resource at the end of the trail. If anything, the duration of trail construction should thus be on average longer. Moreover, ants in our experiment were directly recruited from an active foraging trail. The construction process is likely to be longer when a new physical trail is built from a tunnel entrance because ants have to be recruited from inside the nest, which can be several tens of meters away.

Leaf-cutting ant foraging trails built in pastures are likely to have a lower cost of maintenance than those built in forests because there is no leaf litter accumulating on the trails. Bochynek et al. (2017) thus predicted that foraging trails should be cleared more rapidly among grassland Atta species than among Atta forest species. Grassland Atta species that are specialized on monocotyledons (Fowler et al. 1986) are also likely to build physical trails more rapidly because they use grass as substrate to feed their symbiotic fungus. Unfortunately, no information on the duration of trail construction in leaf-cutting ant forest species is available in the literature to test this prediction. The high variability of trail construction duration we observed is likely to be explained by 

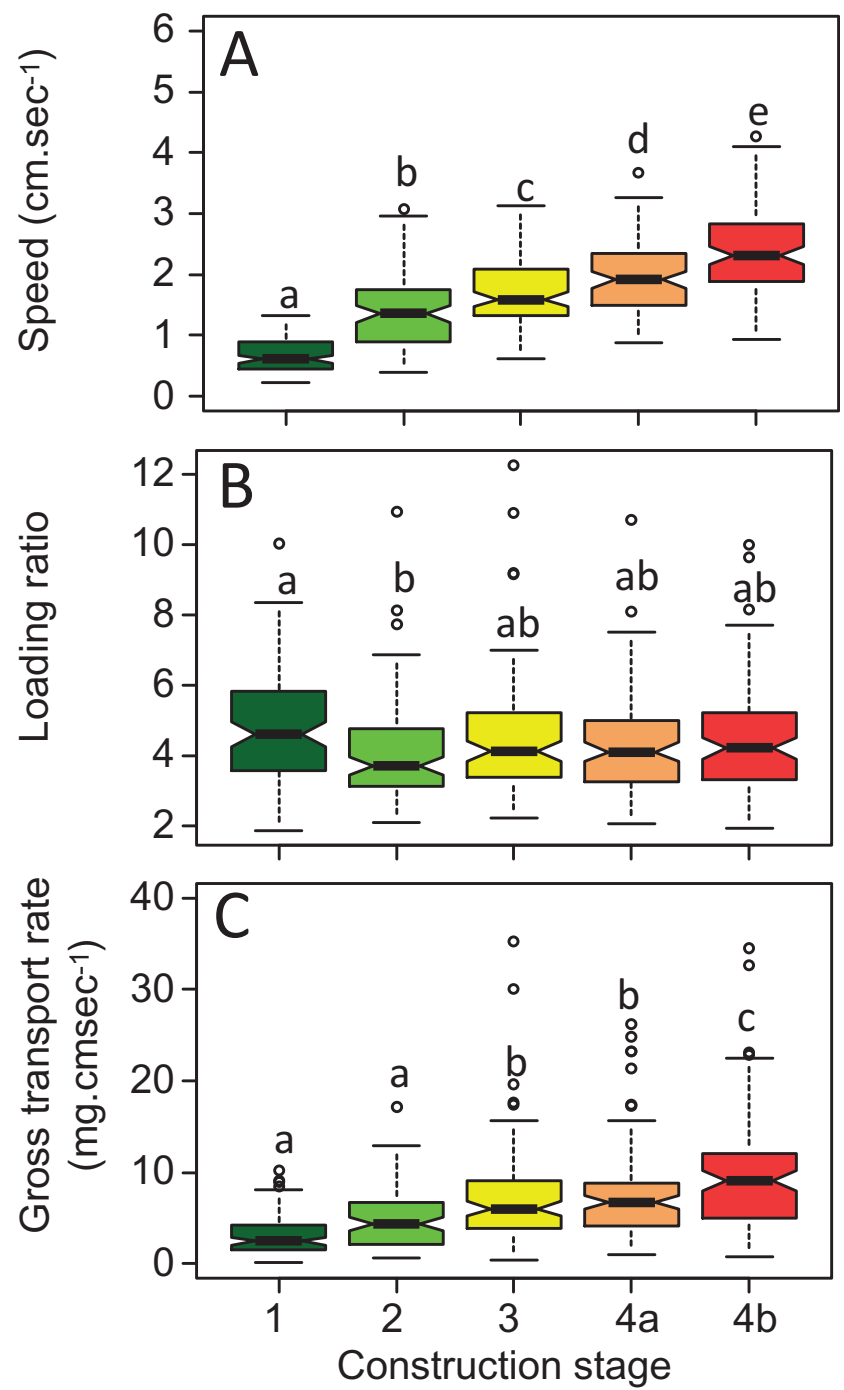

Fig. 4. - Effect of the progress of trail construction on (A) the speed of the ants (with the effects of ant mass, loading ratio and temperature removed), (B) the loading ratio (with the effects of temperature and ant mass removed) and (C) the gross transport rate, calculated as the product of the corrected ant speed and load mass. The lines within the boxplots represent the median and the notches on the boxes indicate the $95 \%$ confidence interval of the median. The lower and upper boundaries of the boxes represent, respectively, the 25 th and 75 th percentiles, while the whiskers extend to the smallest and largest values within 1.5 box lengths. The open circles represent the outliers. The boxes bearing the same letters indicate values that are not significantly different at the $5 \%$ level of significance (post-hoc Tukey test). $N=100$ ants per construction stage.

the variation in meteorological conditions between experiments. Abiotic factors such as rainfall, humidity and temperature are indeed known to strongly influence foraging activity in leaf-cutting ants (Lewis et al. 1974; Caldato et al. 2016). Once the vegetation 

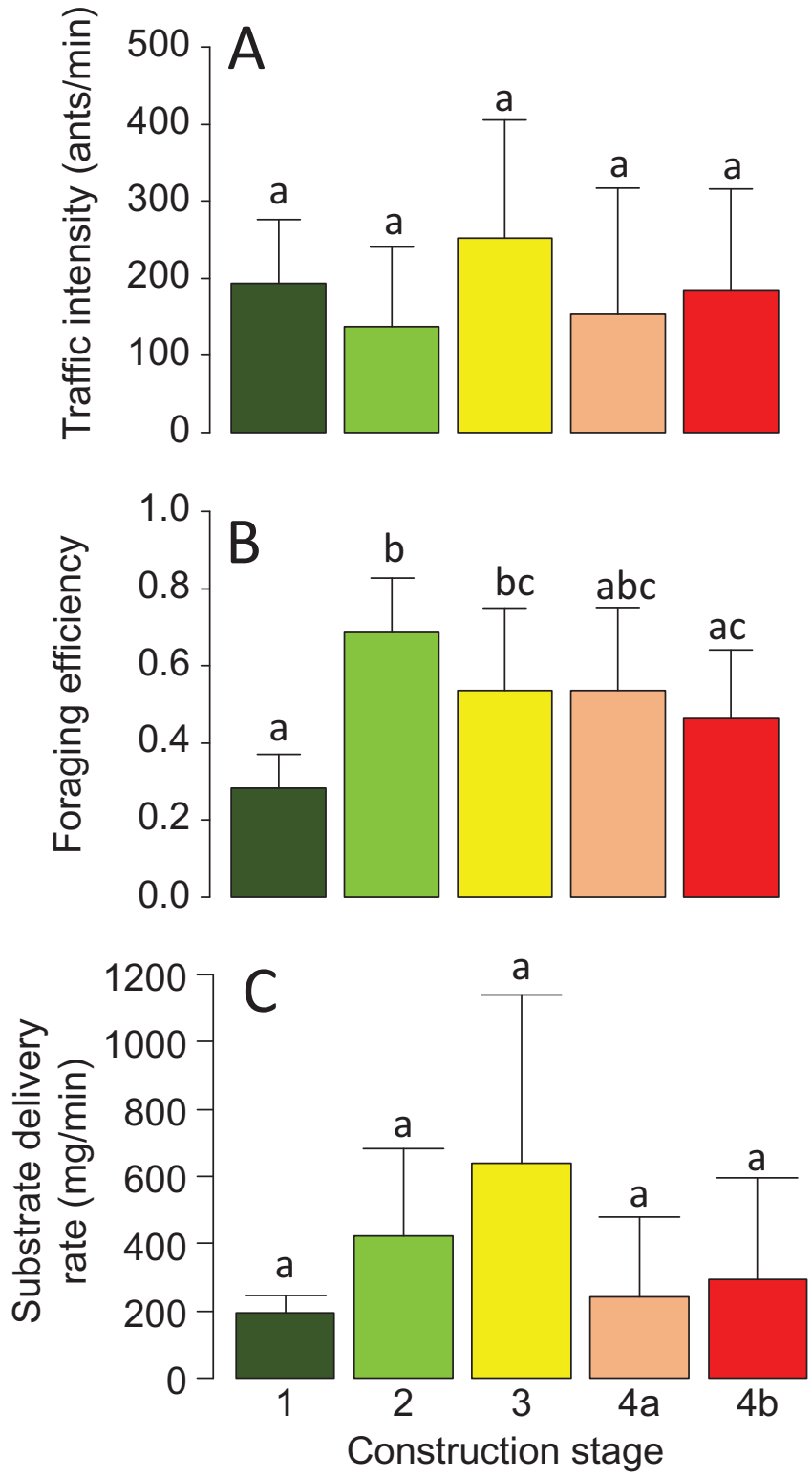

Fig. 5. - Effect of the progress of trail construction on (A) traffic intensity, (B) foraging efficiency and (C) substrate delivery rate. Mean values $\pm \mathrm{CI}_{0.95}$. The bars bearing the same letters indicate values that are not significantly different at the $5 \%$ level of significance (post-hoc Tukey test). $N=5$ counts per construction stage.

has been cut along the trail, rain can then significantly accelerate the clearing of small obstacles from the trail (Weber 1972). Hence, when we placed small objects (ten $3 \mathrm{~cm}$ long wood sticks weighing on average $0.23 \mathrm{~g}$ ) on a complete but inactive physical trail, 
we found that, no matter the quantity of rain (from 1 to $47 \mathrm{~mm}$ ), all objects were removed from the trail $12 \mathrm{hr}$ later. In absence of rain on the other hand all objects remained on the trail. Natural variation in the density of herbaceous vegetation in the pasture can of course also strongly impact the duration of trail construction. According to the model of trunk-trail profitability proposed by Bochynek et al. (2017) the amortization time of a physical trail of less than $10 \mathrm{~m}$ with a $50 \%$ unladen worker fraction and with most unladen workers performing tasks other than clearing, corresponding to the conditions of our experiment, should be less than 10 days. Given the average time of $5 \frac{1}{2}$ $[41 / 2-61 / 2]$ days for trail construction in our experiment this means that a physical trail would be energetically profitable if it used during at least 1 week after its completion. Although the duration of trail usage in leaf-cutting ants is highly variable and depends on a number of factors (meteorological conditions, size of the colony, type of resource exploited) this seems to be generally the case.

The speed of trail construction increased rapidly within the first $48 \mathrm{hr}$ following the initiation of the trail and decreased thereafter (Fig. 2). At this time most of the green grass along the trail was removed and only the layer of dry grass in contact with the soil remained. Because this layer is usually thick and dense, if ants respond with the same probability to a dry as to a green grass blade, it will take them more time to remove the layer of dry grass than the sparsely distributed green grass, leading to a decrease of the speed of trail construction. Other factors could contribute to slow down the construction of the physical trails. First, as the exploitation of the resource proceeds, individual ants probably make several round trips between their nest and the resource and because of the reinforcement they find at the end of the trail they could become more motivated to reach the end of the trail rapidly. Therefore, they could be less prone to stop and to remove the obstacles they encounter on their way to the resource. Second, ants could be less keen to proceed with the construction of the trail once a channel leading to the resource and that can be used as an orienting cue (Shepherd 1982) has been delimited in the vegetation. And third, the speed with which leaf cutting ants construct physical trails could also depend on the quality and the quantity of the resource or on the nutritional needs of the colony. Further investigations are needed to determine the factors involved in the speed of trail construction.

The speed of trail construction was fairly uniform along the trail except for the last part of the trail where it was slightly slower (Fig. 3). This suggests that trail construction is not the result of a coordinated action of a group of specialized workers, taking the form of a construction front progressing along the trail, but rather is a self-organized process that emerges from the response of individual workers to the local stimuli generated by the obstacles they encounter along the trails. Depending on its own response threshold to these stimuli, each ant could have a certain probability of removing an obstacle, with ants with a lower-response threshold performing construction tasks more frequently (Howard 2001). The fact that the construction work progressed more slowly at the end of the trail could be explained by a reduction of the intensity of traffic due to an increased number of ants losing the chemical trail and wandering off the trail. Finally, one could hypothesize that the workers approaching the end of a trail could be more motivated to cut and collect leaf fragments than to clear the trails of obstacles. The fact that the construction of the physical trails proceeded more slowly in their distal part is consistent with the observation that physical trails generally do not end abruptly but bifurcate in a number of small branches. Depending on the state of the vegetation before the beginning of the trail construction, some parts of the trails could also be built faster, explaining why at any moment during their construction, the trails were composed of a patchwork of pieces of terrain corresponding to the different stages of trail construction. 
Ant speed and GTR increased steadily through the different stages of trail construction. Travelling on a completely cleared terrain (stage $4 \mathrm{~b}$ ) allowed ants to increase their speed by a 2.58 [2.25-2.90] factor and their GTR by a 2.02 [1.45-2.59] factor. Most of this increase can be explained by the fact that ants are walking on a smoother substrate and are progressing in an uncluttered environment. The increase we found is not different from the value of 2.29 found by Bochynek et al. (2017) in A. colombica and $A$. cephalotes foraging in the rainforest but is much lower than the four- to ten-fold increase reported by Rockwood and Hubbell (1987) in A. cephalotes foraging in a tropical moist forest. This may be due to the fact that the ants followed outside the trunk trails by these authors were walking on leaf litter, which makes a much coarser and more uneven substrate than the grass mat found on the soil of pastures. The ants followed outside trunk-trails by these authors could also have been scouts returning to a trail after finding a leaf fragment, not ants travelling on uncleared trails, i.e. following a pheromone trail, as in our experiment and that of Bochynek et al. (2017). Other factors may also contribute to the increase in speed we observed for ants walking on cleared trails. Hence, the concentration of trail pheromone on a trail that has been used for some days could be higher, leading to an increase in speed (Czaczkes et al. 2011). Ants may also use the edge of the physical trail as a visual guideline and thus have less sinuous path. Since speed is calculated as the time required by ants to travel a certain distance along the trail, this would result in an increase of its value.

Neither the load carried by ants, nor the ant size distribution, the traffic intensity on the trails, the foraging efficiency, or the substrate delivery rate changed significantly between the initial and final stage of trail construction. One could have hypothesized that ants could compensate for the low GTR at the beginning of trail construction either at the individual level, by a higher probability of collecting a leaf fragment (hence increasing foraging efficiency), or at the colony level, by increasing the intensity of traffic. However, none of these hypotheses was validated. As explained above, trail construction is not homogenous and ants walking along a physical trail are exposed to portions of terrain corresponding to different stages of trail construction. This precludes any possible adjustment at the individual or colony level with the progress of trail construction. The fact that traffic intensity did not vary significantly between the beginning and the end of trail construction whereas the speed of the ants was more than doubled simply means that on a cleared trail a colony needs to mobilize only a fraction of the foraging workers that were mobilized on an uncleared trail to retrieve the same quantity of vegetation within the same interval of time. This fraction is equal to the inverse of the speed increase factor, i.e. about 0.4 . The colony can therefore allocate $60 \%$ of the workers that were mobilized at the beginning of the trail construction (for the trail construction or for collecting vegetation) to other foraging trails or to other tasks, such as processing the vegetation inside the nest. The increase in speed also allows foraging ants to perform more round trips within the same time and thus to increase the amount of vegetation returned to the nest at the end of a foraging day.

Since GTR did not increase significantly when ants were travelling on a trail with exposed root stocks (stage 4a) compared to when they were travelling on a dry grass mat (stage 3), one can wonder why they continue their construction effort beyond stage 3. There can be several explanations to this behaviour. First, removing the dry grass mat along the trail could be worth the effort because, if ants happen to find bare soil below the dry grass, their GTR could increase significantly (Fig. 3C). Second, even if GTR does not increase significantly for ants travelling on root stocks compared with those travelling on a dry grass mat, their speed does. Ants travelling on root stocks increased their speed by a 1.93 [1.61-2.25] factor compared to ants 
travelling on a completely uncleared trail (stage 1). For the average fraction of unladen ants we observed on the trails at this stage of trail construction, i.e. 0.50 (Fig. 5B), this is close to the value of the speed increase factor (around 2) found by Bochynek et al. (2017) beyond which the construction of a physical trail, independent of its length and of the proportion of unladen ants participating in clearing tasks, is expected to become energetically profitable. Third, removing the dry grass mat allows ants to have access to the grass shoots and to cut them before they sprout. Fourth, a complete physical trail is certainly more long-lasting than a partially built physical trail. In fact, even after they have been abandoned for several months, physical trails can easily be found in pastures, especially in the dry season during which the growth of the vegetation is very slow. Leaf-cutting ants are territorial species that deposit a territorial pheromone on their trunk trails (Salzemann \& Jaffe 1990). Long lasting physical trails thus partition the space between neighbouring colonies and contribute to decreasing the frequency of intraspecific agonistic encounters (Fowler \& Stiles 1980; Wirth et al. 2003). This contributes to the payoff of physical trails for the colonies beyond the benefit they provide in terms of food collection. Physical trails can also be rapidly reactivated by the colonies after the regrowth of the vegetation at their end, which allow leaf-cutting ants to pre-empt new resources and speed up their exploitation. Finally, as the properties of trail pheromone in ants are known to depend on the type of substrate on which they are laid (Torgerson \& Akre 1970), future research should also investigate whether the trail pheromone of leaf-cutting ants is more persistent on bare soil or root stocks than on dry grass. If this is true then this would be another benefit of removing the dry grass mat.

To summarize, our observations support the idea that the construction of physical trails in leaf-cutting ants is an emergent phenomenon that results from the uncoordinated removal action by individual workers of the obstacles they encounter on their way to the resource. The use of physical trails allow ants to nearly double their GTR and thus to increase their foraging performance at the individual level. The increase in speed also allows the colony to mobilize less workers to collect the same amount of vegetation within the same interval of time. Finally, as physical trails are long lasting they can become part of the foraging system, allowing leafcutting ants to find and exploit more rapidly the vegetation located at their end after its regrowth.

\section{ACKNOWLEDGEMENTS}

This work was supported by a doctoral grant from the French Ministry of Education to S. Bouchebti and in part by a CAPES/Cofecub Brazil-France cooperation grant (No. 633/09).

\section{DISCLOSURE STATEMENT}

No potential conflict of interest was reported by the authors. 


\section{FUNDING}

This work was supported by the Ministère de l'Education Nationale, de l'Enseignement Superieur et de la Recherche; CAPES/COFECUB [grant number 633/09];

\section{ORCID}

Raphael Vacchi Travaglini (10) http://orcid.org/0000-0002-5404-8136 Vincent Fourcassié (1) http://orcid.org/0000-0002-3605-6351

\section{REFERENCES}

Amante E. 1972. Influência de alguns fatores microclimáticos sobre a formiga saúva Atta laevigata F. Smith, 1858, Atta sexdens rubropilosa Forel, 1908, Atta bisphaerica Forel, 1908 e Atta capiguara Gonçalves, 1944 (Hymenoptera, Formicidae), em formigueiros localizados no estado de São Paulo. [Influence of some microclimatic factors on the leaf-cutting ants Atta laevigata F. Smith, 1858, Atta sexdens rubropilosa Forel, 1908, Atta bisphaerica Forel, 1908 and Atta capiguara Gonçalves, 1944 (Hymenoptera, Formicidae) in colonies located in the state of São Paulo] [PhD Dissertation]. Piracicaba (São Paulo, Brazil): Escola Superior de Agricultura "Luiz de Queiroz", Universidade de São Paulo. Brazilian.

Barton K. 2016. MuMIn: multi-Model Inference. R package version 1.15.6. Available from: http:// CRAN.R-project.org/package=MuMIn

Bates GH. 1950. Track making by man and domestic animals. J Anim Ecol. 19:21-28.

Blake S, Inkamba-Nkulu C. 2004. Fruit, minerals, and forest elephant trails: do all roads lead to Rome? Biotropica. 36:392-401.

Bochynek T, Meyer B, Burd M. 2017. Energetics of trail clearing in the leaf-cutter ant Atta. Behav Ecol Sociobiol. 71:14.

Burd M. 1996. Foraging performance by Atta colombica, a leaf-cutting ant. Am Nat. 148:597-612.

Burd M. 2000. Body size effects on locomotion and load carriage in the highly polymorphic leafcutting ants Atta colombica and Atta cephalotes. Behav Ecol. 11:125-131.

Burd M, Aranwela N. 2003. Head-on encounter rates and walking speed of foragers in leaf-cutting ant traffic. Insectes Soc. 50:3-8.

Burnham K, Anderson D, Huyvaert K. 2011. AIC model selection and multimodel inference in behavioral ecology: some background, observations, and comparisons. Behav Ecol Sociobiol. 65:23-35.

Caldato N, Forti LC, Bouchebti S, Lopes JFS, Fourcassié V. 2016. Foraging activity pattern and herbivory rates of the grass-cutting ant Atta capiguara. Insectes Soc. 63:421-428.

Cerdá X, Angulo E, Boulay R, Lenoir A. 2009. Individual and collective foraging decisions: a field study of worker recruitment in the gypsy ant Aphaenogaster senilis. Behav Ecol Sociobiol. 63:551-562.

Cevallos Dupuis CE, Harrison JF. 2016. Trunk trail maintenance in leafcutter ants: caste involvement and effects of obstacle type and size on path clearing in Atta cephalotes. Insectes Soc. 64:189-196.

Chauvin R. 1962. Observations sur les pistes de Formica polyctena. [Observations on the trails of Formica polyctena]. Insectes Soc. 12:311-321. French.

Clay NA, Bauer M, Solis M, Yanoviak SP. 2010. Arboreal substrates influence foraging in tropical ants. Ecol Entomol. 35:417-423.

Czaczkes TJ, Grüter C, Jones SM, Ratnieks FLW. 2011. Synergy between social and private information increases foraging efficiency in ants. Biol Lett. 7:521-524. 
Delabie J, Alves HSR, Reuss-Strenzel GM, do Carmo AFR, do Nascimento IC. 2011. Distribuição das formigas-cortadeiras do gêneros Acromyrmex e Atta no novo mundo. [Distribution of the leaf-cutting ants of the genus Acromyrmex and Atta in the New World]. In: Della Lucia TMC, editor. Formigas cortadeiras: da bioecologia ao manejo. Viçosa (Brazil): Universidade Federal de Viçosa; 80-101. Brazilian.

Farji-Brener AG, Barrantes G, Laverde O, Fierro-Calderon K, Bascope F, Lopez A. 2007. Fallen branches as part of leaf-cutting ant trails: their role in resource discovery and leaf transport rates in Atta cephalotes. Biotropica. 39:211-215.

Fewell JH. 1988. Energetic and time costs of foraging in harvester ants, Pogonomyrmex occidentalis. Behav Ecol Sociobiol. 22:401-408.

Fowler HG, Forti LC, Pereira V, Saes NB. 1986. Economics of grass-cutting ants. In: Lofgren CS, Vander Meer RK, editors. Fire ants and leaf-cutting ants. Biology and management. Boulder (CO): Westview Press; p. 123-145.

Fowler HG, Stiles E. 1980. Conservative resource management by leaf-cutting ants? The role of foraging territories and trails, and environmental patchiness. Sociobiology. 5:25-41.

Freeman BM, Chaves-Campos J. 2016. Branch width and height influence the incorporation of branches into foraging trails and travel speed in leafcutter ants Atta cephalotes (L.) (Hymenoptera: Formicidae). Neotrop Entomol. 45:258-264.

Gissel Nielsen M. 2001. Energetic cost of foraging in the ant Rhytidoponera aurata in tropical Australia. Physiol Entomol. 26:248-253.

Gösswald K. 1943. Das Strassensystem der Waldameisenarten. [The route system of wood ants]. Z Morphol Ökol Tiere. 40:37-59. German.

Halsey LG. 2016. Terrestrial movement energetics: current knowledge and its application to the optimising animal. J Exp Biol. 219:1424-1431.

Hothorn T, Bretz F, Westfall P. 2008. Simultaneous inference in general parametric models. Biom J. 50:346-363.

Howard JJ. 2001. Costs of trail construction and maintenance in the leaf-cutting ant Atta columbica. Behav Ecol Sociobiol. 49:348-356.

Hurlbert AH, Ballantyne F, Powell S. 2008. Shaking a leg and hot to trot: the effects of body size and temperature on running speed in ants. Ecol Entomol. 33:144-154.

Kost C, De Oliveira EG, Knoch TA, Wirth R. 2005. Spatio-temporal permanence and plasticity of foraging trails in young and mature leaf-cutting ant colonies (Atta spp.). J Trop Ecol. 21:677-688.

Lewis T, Pollard GV, Dibley GC. 1974. Micro-environmental factors affecting diel patterns of foraging in the leaf-cutting ant Atta cephalotes (L.) (Formicidae: Attini). J Anim Ecol. 43:143-153.

Lopez F, Acosta FJ, Serrano JM. 1993. Responses of the trunk routes of a harvester ant to plantdensity. Oecologia. 93:109-113.

Loreto RG, Hart AG, Pereira T, Freitas M, Hughes D, Simon E. 2013. Foraging ants trade off further for faster: use of natural bridges and trunk trail permanency in carpenter ants. Naturwissenschaften. 100:957-963.

Moreira AA, Forti LC, Andrade AP, Boaretto MAC, Lopes JFS. 2004. Nest architecture of Atta laevigata (F. Smith, 1858) (Hymenoptera: Formicidae). Stud Neotrop Fauna Environ. 39:109-116.

Nakagawa S, Schielzeth H. 2013. A general and simple method for obtaining $\mathrm{R}^{2}$ from generalized linear mixed-effects models. Methods Ecol Evol. 4:133-142.

R Development Core Team. 2015. R: A language and environment for statistical computing. Vienna (Austria): R Foundation for Statistical Computing. Available from: http://www.R-project.org/

Rockwood LL, Hubbell SP. 1987. Host-plant selection, diet diversity, and optimal foraging in a tropical leafcutting ant. Oecologia. 74:55-61.

Rudolph SG, Loudon C. 1986. Load size selection by foraging leaf-cutter ants (Atta cephalotes). Ecol Entomol. 11:401-410.

Sales TA, Hastenreiter IN, Almeida NG, Lopes JFS. 2015. Fast food delivery: is there a way for foraging success in leaf-cutting ants? Sociobiology. 62:513-518.

Salzemann A, Jaffe K. 1990. On the territorial behavior of field colonies of the leaf-cutting ant Atta laevigata (Hymenoptera, Myrmicinae). J Insect Physiol. 36:133-138.

Shepard ELC, Wilson RP, Rees WG, Grundy E, Lambertucci SA, Vosper SB. 2013. Energy landscapes shape animal movement ecology. Am Nat. 182:298-312. 
Shepherd JD. 1982. Trunk trails and the searching strategy of a leaf-cutter ant, Atta colombica. Behav Ecol Sociobiol. 11:77-84.

Stäger R. 1936. Topographische Konstanz der Strassen bei Formica rufopratensis. [Topographical constancy in the trail system of Formica rufopratensis]. Bull Soc Entomol Suisse. 16:679_ 684. German.

Torgerson RL, Akre RD. 1970. The persistence of army ant chemical trails and their significance in the Ecitonie-Ecitophile association (Formicidae: Ecitonini). Melanderia. 5:1-28.

Traniello JFA, Beshers SN. 1991. Maximization of foraging efficiency and resource defense by group retrieval in the ant Formica schaufussi. Behav Ecol Sociobiol. 29:283-289.

Weber NA. 1972. Gardening ants: the Attines. Philadelphia (PA): Memoirs of the American Philosophical Society.

Wetterer JK. 1990. Diel changes in forager size, activity, and load selectivity in a tropical leafcutting ant, Atta cephalotes. Ecol Entomol. 15:97-104.

Wirth R, Herz H, Ryel RJ, Beyschlag W, Hölldobler B. 2003. Herbivory of leaf-cutting ants - A case study on Atta colombica in the tropical rainforest of Panama. Berlin: Springer-Verlag.

Zollikofer C. 1994. Stepping patterns in ants III. Influence of load. J Exp Biol. 192:119-127.

Zuur AF, Hilbe JM, Ieno EN. 2015. A beginner's guide to GLM and GLMM with R - A frequentits and Bayesian perspective for ecologists. Newburgh (UK): Highland Statistics Ltd. 